\title{
A economia como objeto socialmente construído nas análises regulacionista e da Economia Social de Mercado
}

\author{
The economy as a socially constructed object in the \\ regulationnist and the Social Market Economy analyses
}

MIGUEL BRUNO

RICARDO CAFFE*

RESUMO: O artigo discute os argumentos ontológicos em defesa das especificidades dos fenômenos econômicos, comparativamente àqueles encontrados nos sistemas inorgânico e orgânico. Sua posição epistemológica é antipositivista e antineoclássica, sustentando que a tentativa de naturalizar os sistemas socioeconômicos, que marca a Economia, desde os fisiocratas, tem contribuído para enfraquecer seu potencial heurístico, explicativo e preditivo. A problemática é desenvolvida partindo-se de uma análise comparativa entre a Teoria da Regulação e a Economia Social de Mercado, correntes teóricas onde o conceito de instituição e a historicidade inerente às relações de produção e de distribuição são consideradas centrais. Diferentemente dos objetos da natureza, cujas regularidades e processos não foram originalmente criados pela práxis humana, o objeto econômico é social e politicamente construído e precisa ter, portanto, estatuto teórico-metodológico específico. Em consequência, a pertinência das teorias em face das regularidades micro e macroeconômicas observadas não pode ser alcançada por uma abordagem axiomática que faz da Economia uma ciência essencialmente lógico-dedutiva e a-histórica por construção, tampouco pela pressuposição da existência de leis gerais invariantes, puramente econômicas e inescapáveis.

PALAVRAS-CHAVE: Metodologia; Epistemologia da Economia; Teoria da Regulação; Economia Social de Mercado; análise institucionalista.

ABSTRACT: This paper discusses the ontological arguments in favor of a methodological approach that recognizes the specific characteristics of economic phenomena, compared with those found in inorganic and organic systems. Their epistemological position is antipositivist and anti-neoclassical because it rejects the attempt to analyses the socio-economic

\footnotetext{
* Professor pesquisador do Programa de Pós-Graduação em População, Território e Estatísticas Públicas da ENCE-IBGE. E-mail: Miguel.pbruno@gmail.com; Professor pesquisador do Programa de PósGraduação em Economia - Universidade Federal da Bahia- PPGE/UFBA, e-mail: ricardo.caffe@gmail. com. Submetido:17/Dezembro/2015; Aprovado: 4/Março/2016.
} 
system by analogy with the physical and biological systems. In fact, this is a methodologic mistake, which occurs since the birth of Economic Science with the Physiocracy. These physicalist and organicist views contributes to weaken the heuristic, explanatory and predictive ability of the economic theories. To explore this issue, the present paper starting with a comparative analysis of the Regulation Theory and the Social Market Economy, theoretical currents where the concept of the institution and the historicity inherent in the production and distribution relationships are considered central. Unlike the objects of Physics and Biology, whose regularities and processes were not originally created by the human praxis, the economic object is socially and politically constructed and must have therefore specific theoretical and methodological status. Consequently, the relevance of the theories in the face of the observed economic regularities cannot be achieved by an axiomatic approach that makes the economy an essentially logical-deductive science and ahistorical by construction, nor the assumption of the existence of invariant general laws, purely economic and inescapable.

KEYWORDS: methodology; epistemology of Economic science; Regulation theory; Social market economy; Institutionalist analysis

JEL Classification: A11; B1; B2; B4; B5.

\section{INTRODUÇÃO}

Este artigo discute os argumentos ontológicos e epistemológicos em defesa das especificidades dos fenômenos econômicos, comparativamente aos fenômenos encontrados nos sistemas inorgânico e orgânico. Consequentemente, sua posição epistemológica é antipositivista e antineoclássica, sustentando que a tentativa de naturalizar os sistemas socioeconômicos, que marca o nascimento da Economia, desde os fisiocratas, tem contribuído para enfraquecer seu potencial heurístico, explicativo e preditivo.

A problemática é desenvolvida a partir de uma análise comparativa entre as abordagens propostas pela Teoria da Regulação e pela Economia Social de Mercado, explicitando seus pontos de convergência e implicações teóricas. Nesse contexto, duas características fundamentais do objeto econômico são explicitadas: a) relações econômicas são relações de poder de indivíduos, grupos e classes sociais sobre os demais membros da sociedade. Essas relações não estão inscritas em nenhuma suposta "ordem espontânea e natural inerente às economias mercantis e concorrenciais", não podendo ser derivadas de leis invariantes ou de tendências eternas e inescapáveis, em geral, invocadas para legitimar privilégios de classe ou de setores econômicos; b) essas relações e suas possíveis consequências adversas para o conjunto da sociedade podem ser alteradas, ou seus efeitos atenuados, graças à interveniência de leis, normas e instituições que regulem mercados, finanças e as próprias relações sociais de produção e de apropriação do excedente econômico.

A segunda seção discorre sobre os limites epistemológicos do positivismo quando aplicado aos objetos da Ciência Econômica. O pensamento econômico liberal é uma de suas consequências e a corrente fisiocrática uma, de suas primei- 
ras expressões sistematizadas. Na terceira seção, o objeto econômico é caracterizado fora dos cânones positivistas, graças à apreensão ontológica de suas especificidades, comparativamente aos objetos dos sistemas físicos e biológicos. A quarta seção faz uma comparação da Economia Social de Mercado (ESM), corrente teórica alemã que fundamenta vários dos papéis do Estado, com a Teoria da Regulação (TR),francesa, cujos trabalhos atuais se inscrevem em uma macroeconomia histórica e institucionalista. Além de compartilharem várias interpretações acerca do objeto econômico e das economias capitalistas, essa convergência teórica só foi possível porque, ontologicamente, foi rejeitada sua redução positivista aos objetos dos sistemas inorgânicos e orgânicos. Os processos de teorização tornam-se abertos e adaptáveis à evolução socioeconômica concreta e não visam à detecção ou imposição de um único padrão eficiente, universalizável e trans-histórico dessas economias. A quinta seção conclui a análise da problemática proposta fazendo um balanço final das ideias discutidas.

\section{OS LIMITES EPISTEMOLÓGICOS DO POSITIVISMO E A CONCEPÇÃO LIBERAL-NATURALISTA DAS RELAÇÕES ECONÔMICAS}

Influenciado por ambos os autores fisiocratas, Adam Smith nunca argumentou em prol de um Estado mínimo, tal como, em geral, supõe a vulgata neoliberal de A Riqueza das Nações. Smith, de fato, nunca foi adepto de algum tipo de ultraliberalismo. Assim como faria mais tarde David Ricardo, Smith reconhecia que o conflito distributivo é inerente ao processo capitalista de acumulação, ocupando um lugar central nas questões econômicas mais importantes, tal como a partilha do excedente econômico entre capital e trabalho assalariado. No capítulo 8 dessa obra, argumentou:

"Os trabalhadores desejam ganhar o máximo possível, os patrões, pagar o mínimo possível. Os primeiros procuram associar-se entre si para levantar os salários do trabalho, os patrões fazem o mesmo para baixá-los. Não é difícil prever qual das duas partes, normalmente, leva vantagem na disputa e no poder de forçar a outra a concordar com as suas próprias cláusulas. [...]. Em todas essas disputas, o empresário tem capacidade para aguentar por muito mais tempo. Um proprietário rural ou um comerciante, mesmo sem empregar um trabalhador sequer, conseguiria viver um ano ou dois com o patrimônio que já puderam acumular. Ao contrário, muitos trabalhadores não conseguiriam subsistir uma semana, poucos conseguiriam subsistir um mês e dificilmente algum conseguiria subsistir um ano, sem emprego. Os patrões estão sempre e em toda parte em conluio tácito, mas constante e uniforme para não elevar os salários do trabalho acima de sua taxa em vigor. [...]. Frequentemente, os patrões fazem conchavos destinados a baixar os salários do trabalho, mesmo aquém de sua taxa em vigor" (p. 64). 
Esse reconhecimento do conflito distributivo foi completamente esvaziado das análises marginalistas e neoclássicas ${ }^{1}$, substituindo as classes sociais produtivas, trabalhadores e capitalistas, pelo conceito, considerado teoricamente "neutro", de fatores de produção (trabalho e capital). Pautadas pela influência positivista com sua busca da neutralidade axiológica e definição de um nível de análise puramente econômico e trans-histórico, o conceito de classe social fora visto como inconveniente por abrigar conteúdos considerados como extraeconômicos (político-ideológicos, culturais, sociológicos, institucionais etc.).

No plano das análises, a aplicação dos princípios metodológicos do positivismo em Economia teve como consequência a tentativa de "naturalização" dos fenômenos econômicos e seu tratamento a-histórico, como se houvesse leis econômicas com o mesmo estatuto teórico das leis físicas como as da gravidade. Entretanto, o processo de objetivação que toda ciência busca não é capaz de eliminar, por uma decisão metodológica (necessariamente subjetiva) tida como a única pertinente (a metodologia positivista), conteúdos subjetivos e ideológicos para torná-la supostamente imparcial ou axiologicamente neutra; pois essa escolha nunca é isenta e nunca poderá provir de um observador livre de prenoções, preconceitos ou destituído de uma visão de mundo individual. Agentes e estruturas em interação, sujeitos cognoscentes e seus objetos de pesquisa, necessariamente mantêm relações mutuamente condicionantes, notadamente em ciências sociais como a Economia. Além disso, as relações sociais não estão inscritas em nenhum tipo de determinismo inescapável produzido por forças de um mercado completamente impessoal e trans-histórico, que imporia à civilização apenas duas alternativas: ou aceitar resignadamente suas sempre benéficas determinações ou violá-las e sucumbir aos problemas dos desequilíbrios e ineficiências econômicas.

No campo neoclássico e walrasiano, essa ontologia naturalista da sociedade e da economia gerou inúmeras contradições no seio das análises, hipóteses e teorias propostas. Imprimiu à abordagem dominante um caráter axiomático e lógico-dedutivo que, antes de positiva, tornou-se muito mais normativa, na medida em que suas proposições não partiam de comportamentos historicamente observados dos agentes, mas como eles poderiam e deveriam atuar eficientemente se os mercados fossem de fato concorrenciais. Nesse mundo econômico assim teorizado, o ótimo econômico coincidiria com o ótimo social, desde que as leis consideradas invariantes da produção e da distribuição da riqueza fossem efetivamente respeitadas em suas determinações estruturais. Mas num tal contexto, os indivíduos são reduzidos a atores conclamados a desempenhar passivamente os papéis que lhes são designados pelo funcionamento mecanicista de leis econômicas inescapáveis e, evidentemente, não poderiam ser sujeitos de sua própria história, agentes conscientes e transformadores em sua prática sociopolítica. A justiça distributiva seria consequência mesma do fato de os agentes participantes do processo produtivo recebe-

\footnotetext{
${ }^{1}$ Distingue-se aqui a abordagem neoclássica da marginalista, uma vez que a escola austríaca é marginalista sem defender o tratamento analítico da escola neoclássica.
} 
rem o que fazem realmente jus de acordo com suas respectivas contribuições ao produto. Os salários pagos refletiriam as produtividades marginais do trabalho e os lucros, as produtividades marginais do capital, de acordo com a teoria microeconômica neoclássica, não havendo espaço para conflitos distributivos ou entre classes sociais.

A leitura de A Riqueza das Nações permite inferir que para Smith, a "mão invisível" do mercado só poderia funcionar sobre a base de instituições, leis, regras e normas adequadas. A lógica mercantil não se reproduziria sem regras disciplinadoras, pois o caráter conflituoso dos interesses individuais tenderia a se sobrepor à possibilidade de sua compatibilidade global ou social. Afinal, de um ponto de vista lógico, a concorrência sem limites conduz, necessariamente, ao seu contrário, o oligopólio ou o monopólio, já que agentes economicamente mais fortes tendem a conquistar as fatias de mercado dos demais. Uma questão que parece tender a um consenso na teoria econômica, desde que o direito de defesa da concorrência foi reconhecido no campo jurídico-normativo e dá suporte às ações regulatórias do poder público.

O problema epistemológico básico provocado pelo positivismo na Ciência Econômica decorre de sua recusa a uma abordagem ontológica dos objetos estudados. Por isso defende a unicidade do método científico, isto é, todas as ciências deveriam utilizar o mesmo método experimental ou observacional, pressupondo-o livre de julgamentos de valor, neutro, imparcial e livre de conteúdos ideológicos. A existência de propriedades específicas ao objeto estudado, se social, físico, químico ou biológico, não é considerada um fator impeditivo para a aplicação de uma mesma metodologia. Nesta ontologia da sociedade, as relações econômico-mercantis seguiriam regularidades autônomas, assimiladas, no plano da teoria, às regularidades observadas em fenômenos da natureza. As ações humanas deveriam segui-las em prol do bem-estar geral. Poderiam apenas aperfeiçoá-las, pois não conseguiriam alterá-la sem provocar consequências negativas sobre a produção e alocação eficiente dos recursos disponíveis. O pensamento liberal-econômico da Escola Austríaca compartilha essa perspectiva, pois o capitalismo é o melhor sistema para a sociedade, pois evoluiu "espontaneamente" após séculos de história humana, sem nenhum plano deliberado, subproduto de algum tipo de voluntarismo. Então, paradoxalmente, as ações conscientes dos seres humanos orientadas pelos conhecimentos científicos e tecnológicos estariam aptas apenas a facilitar o funcionamento de mercados e suas "leis" derivadas, preservando, portanto, a essência de uma sociedade mercantil-capitalista, modelo civilizatório historicamente insuperável.

Essa concepção fisicalista do fenômeno econômico, que tácita e ideologicamente visa eternizar o capitalismo, apresenta-se em uma contradição flagrante com o próprio argumento positivista da existência de leis invariantes em Economia. O objeto sob análise, composto por regularidades ou fenômenos socioeconômicos, é estruturalmente dependente da subjetividade do observador, de sua racionalidade e dos demais que com ele interagem, validando o status teórico conferido atualmente ao conceito de expectativas no âmbito da Macroeconomia. Mais do 
que atores passivos e cumpridores de scripts predefinidos por forças impessoais do mercado, são também criadores de novas regras e regularidades fazendo desse mercado uma construção institucional; seja aceitando-as, seja insurgindo-se contra elas e transformando as estruturas e processos socioeconômicos que constituem as bases da existência das civilizações.

Nesse sentido, a teoria econômica neoclássica e sua vertente walrasiana foram as mais influenciadas pelo sucesso da Mecânica clássica newtoniana. Isso fica claro quando se constata que os conceitos de equilíbrio, inércia, histerese etc. foram todos eles importados, por analogia direta e sem nenhuma mediação ontológica, dessa ciência. Auguste Comte, criador do positivismo na França do século 19, chegou a argumentar:

“[...] entendo por Física Social, a ciência que tem por objeto o estudo dos fenômenos sociais considerados dentro do mesmo espírito dos fenômenos astronômicos, físicos, químicos e fisiológicos, quer dizer, como sujeitos às leis naturais invariáveis, ${ }^{2}$ cuja descoberta é o objetivo específico de suas pesquisas."

Entretanto, as comparações com as ciências da natureza são ontologicamente inadequadas e, por isso, epistemologicamente equivocadas para a produção de teorias consistentes com a realidade social e que, efetivamente, contribuam para o avanço do conhecimento científico em Economia.

Quanto à analogia com a Astronomia é inadequada porque, diferentemente do que ocorre com as relações econômicas, as interferências dos cientistas são ainda muitíssimo limitadas para, por exemplo, pretender alterar os movimentos dos astros, impondo-lhes novos padrões de evolução. Quanto às segundas, mesmo que a Bioquímica e a Medicina já possuam conhecimento científico que lhes permitem grande margem de atuação para interferir em regularidades fisiológicas, ambas possuem em comum o fato de lidarem com objetos e fenômenos cujas regularidades comportamentais não se originaram, não dependem ou não foram criadas por nenhuma atividade consciente do trabalho humano. Processos bioquímicos ou fisiológicos se desenvolvem à revelia dos seres humanos que não os estabeleceram pelo trabalho consciente. Além disso, nessa área, os avanços para a saúde da espécie humana implicam o conhecimento, respeito e reprodução das regularidades necessárias para manter vivo o corpo humano, tal como foram estabelecidas pelo código genético e por milhares de anos de evolução.

Como observa Löwy (1994, p. 24), essa ontologia naturalista da economia e da sociedade já estava presente nas ideias do economista Jean-Baptiste Say (mais conhecido pela proposição segundo a qual "a oferta cria sua própria procura" ou "lei dos mercados de Say"). Observa Löwy que, em seu Tratado de Economia Política, de 1803, Say argumentou:

\footnotetext{
${ }^{2}$ Os grifos são nossos.
} 
"As leis gerais que regulam as ciências políticas e morais existem a despeito das disputas... Elas derivam da natureza das coisas, tão seguramente quanto as leis físicas do mundo.”

Comte cita frequentemente os fenômenos econômicos como exemplos destas "leis naturais invariáveis" da sociedade. A concentração de capital com o subsequente aumento das desigualdades sociais decorreria dessas leis imutáveis e deve ser respeitada. Um mote muito conveniente para justificar o status quo e levar os homens a sentirem-se impotentes e cruzarem os braços diante de uma realidade tida não apenas como inalterável, mas necessária e inescapável. Aqui o determinismo físico-natural é transposto abusivamente ao sistema socioeconômico para postular que seu funcionamento se daria segundo leis como as da gravidade ou as da termodinâmica. À sociedade caberia apenas o papel passivo de respeitá-las e preservá-las contra interferências ou fatores intrusos provindos do Estado ou de indivíduos que ameacem interromper o "curso normal e natural das coisas", pois não se conformam com as estruturas estabelecidas.

Outras epistemologias podem ser consideradas, como a noção de paradigma de Thomas Kuhn e os Programas de Pesquisa Científica propostos por Imre Lakattos $^{3}$. Esta última é particularmente importante porque sustenta que toda teoria possui um núcleo duro axiomático (hard core, composto pelos princípios fundadores, como a racionalidade substantiva do homo oeconomicus, a eficiência postulada dos mercados concorrenciais, o princípio de maximização) e um cinturão protetor (protective belt) em que estão as hipóteses complementares ou auxiliares da teoria. Quando se trata de confrontar as teorias econômicas com os dados empíricos, são essas hipóteses auxiliares que são testadas e, eventualmente, refutadas. No entanto, o economista, como regra, não abre mão de sua "crença teórica", instalada confortavelmente no "núcleo duro" (princípios e hipóteses fundadoras) da teoria. Resistindo ao máximo expô-los aos dados empíricos, os mantêm ao abrigo da realidade graças à proteção proporcionada pelo "cinturão protetor" (hipóteses secundárias e auxiliares). Estas últimas é que poderão ser confrontadas com os dados empíricos, mediante análise econométrica.

Blaug (1998) observa que, em Física, por exemplo, os cientistas são capazes de abandonar teorias, hipóteses, princípios se os testes experimentais não os corroborarem. Mas os economistas tendem a se agarrar a seus princípios preferidos; e se o teste econométrico não corroborar a teoria, eles buscam uma hipótese $a d$ hoc para "solucionar" o impasse. O físico normalmente leva muito mais a sério o teste de suas teorias do que o economista convencional. Para este autor, estariam equivocados os que pensam que a Economia moderna está se aproximando cada vez mais da Física. E cita McCloskey, que observa que, nas universidades, o depar-

\footnotetext{
${ }^{3}$ Apesar do presente artigo não ter por objetivo abordar as diversas correntes epistemológicas em suas implicações para a Ciência Econômica, pode-se destacar a crítica de Karl Popper (1980) quanto à suposta existência de leis históricas universais, análogas às leis físicas ou naturais.
} 
tamento mais procurado pelos economistas da mainstream analysis não é o de Física, mas o de Matemática, onde os testes empíricos são desnecessários.

Isso implica reduzir a Ciência Econômica a uma ciência puramente teórica cujos fenômenos poderiam ser tratados partindo-se de uma visão axiomática ou um ponto de vista puramente lógico-dedutivo com base em comportamentos individuais, microeconômicos, postulados como se fossem traduções fiéis do funcionamento da realidade econômica concreta. Uma démarche característica do enfoque walrasiano e seus desenvolvimentos e variantes contemporâneas. Coroamento do positivismo lógico em Economia, esta abordagem converte-se em um obstáculo epistemológico flagrante, segundo a epistemologia de Bachelard ${ }^{4}$. Incapaz de representar satisfatoriamente os comportamentos socioeconômicos concretos no plano das análises, torna-se um veículo de conteúdo ideológico, porquanto apologético de um capitalismo, na prática, inexistente, que funcionaria sob livre concorrência, movida essencialmente pela racionalidade otimizadora de lucros e utilidade de agentes individuais.

\section{A ECONOMIA É UM OBJETO SOCIAL, POLÍTICA E INSTITUCIONALMENTE CONSTRUÍDO}

Diferentemente do que ocorre nos sistemas inorgânicos e orgânicos, as regularidades ou "leis" comportamentais observadas nos sistemas socioeconômicos não são independentes das ações humanas, não são eternas. Pelo contrário, as regularidades econômicas não podem existir sem a consciência dos agentes econômicos e suas interações sociais. Não se tornam inteligíveis senão pelo reconhecimento de sua historicidade.

Isso não significa que os seres humanos possam construir ou estabelecer quaisquer relações que desejarem entre si e com a natureza. Significa que as regularidades econômicas não se reproduzem sem a consciência e os papéis ativos de produtores e consumidores, embora a atuação dos seres humanos esteja limitada pelo desenvolvimento científico-tecnológico alcançado pela sociedade e pelas restrições estruturais legadas do passado histórico e recente. Além disso, os sistemas inorgânico (físico) e orgânico (biológico) lhes impõem restrições objetivas porque compõem o cenário sobre o qual agem produtores e consumidores.

Os graus de liberdade disponíveis derivam das necessidades materiais que possam ser satisfeitas pelo inescapável metabolismo ser humano-natureza - mediado pelo desenvolvimento científico e tecnológico - e que é a base da sobrevivência da espécie humana. Essa percepção já se encontra em O Capital, quando

\footnotetext{
${ }^{4}$ A noção de obstáculo epistemológico proposta por Bachelard (1996) refere-se a conceitos, hipóteses, atitudes mentais convencionais, reproduzidas e cristalizadas pelo saber instituído e institucionalizado nas Ciências Econômicas e que, por isso mesmo, bloqueiam novos modos de pensar e as alternativas teóricas ao modelo neoclássico-positivista em Economia.
} 
Marx recorre ao conceito de metabolismo social, como atividade transformadora da natureza e dos próprios seres humanos, e cuja base é o processo de trabalho. Mas esse metabolismo não é factível a partir de sujeitos autossuficientes, isolados e independentes, que se relacionariam apenas com objetos (bens) e com a natureza (insumos) - tal qual Robinson Crusoé, mascote da concepção individualista e positivista neoclássica. Relações sociais de produção e de distribuição são necessárias e historicamente determinadas; são o substrato material de todo processo produtivo e fundamento da concepção clássica de divisão do trabalho.

Uma definição não marginalista e não neoclássica de Economia poderia então ser considerada: a Economia é a ciência das relações sociais de produção e de distribuição que viabilizam o necessário metabolismo ser humano-natureza, com suas diferentes formas possíveis de evolução organizacional e sob critérios de sustentabilidade não apenas econômicos, mas também socioambientais. Mas essas relações sociais não derivam e não estão inscritas em nenhum determinismo físico ou biológico, pois são estruturadas a partir de relações de poder, cujos conteúdos sócio-político-institucionais dependem de decisões deliberadas de sujeitos humanos agindo, conscientemente, uns sobre os outros e sobre a natureza. Embora sempre mediatizadas pelas restrições do meio ambiente natural, as relações de produção e de distribuição são também transformadas pela ciência e tecnologia, ampliando as liberdades humanas e o potencial produtivo das sociedades.

Contra a posição ontológica implícita no positivismo e sua unicidade do método, argumentou Castoriadis (2008):

“[...] ou há, verdadeiramente, leis da história - e, nesse caso, uma genuína atividade humana é impossível, a não ser, na melhor das hipóteses, enquanto técnica; ou então os homens fazem a sua história - e a tarefa do trabalho teórico não é mais a descoberta de 'leis', mas a elucidação das condições que enquadram e delimitam essa atividade, das regularidades ${ }^{5}$ que ela pode apresentar etc."

A capacidade de intervir no meio ambiente natural de maneira a transformá-lo e adequá-lo às suas necessidades é o que define o trabalho como atividade especificamente humana consciente e por isso a humanidade pôde criar civilizações. As diversas culturas que caracterizam a riqueza das civilizações não estão inscritas em nenhum determinismo trans-histórico e não podem, portanto, ser deduzidas de leis e tendências eternas e invariantes. Nesse contexto, o positivismo aplicado em Ciência Econômica contradiz seus próprios pressupostos referentes à capacidade humana de produzir conhecimento verdadeiramente científico. Nessa ontologia, a liberdade humana está restrita apenas às ações que garantam a reprodução dessas

\footnotetext{
${ }^{5}$ O grifo é nosso. Essa é a posição epistemológica sustentada pela Teoria da Regulação para a qual não há leis econômicas gerais ou universais e o trabalho do economista deveria concentrar-se na detecção dessas regularidades estruturais que respondem pela dinâmica econômica, mas que são vulneráveis à ação dos homens na história.
} 
regularidades sociais, assimiladas, equivocadamente, às leis ou regularidades físicas e biológicas, que, no entanto, são independentes da consciência e das ações humanas.

A declaração de Compte (apud Löwy, 1994), fundador do positivismo, é bem representativa dessa posição:

"há que se preparar os proletários para respeitarem, e mesmo reforçarem, as leis naturais da concentração do poder e da riqueza" ${ }^{6 ”}$.

Löwy lembra que Marx lhe dedicou uma nota irônica no primeiro livro de $O$ Capital:

"Auguste Compte e sua escola procuraram demonstrar a eterna necessidade dos senhores do capital; eles teriam, tão bem quanto e com as mesmas razões, podido demonstrar a eterna necessidade dos senhores feudais."

A liberdade humana para estabelecer suas relações de produção e de distribuição está logicamente condicionada e limitada por relações de poder e pelos conteúdos ideológicos que atravessam todas as áreas das ciências e não apenas pelas restrições impostas pelo mundo natural. Mas, o importante a ser ressaltado é que existe ampla margem de criatividade para a configuração dessas relações e que elas se revestem de características específicas no nível das economias nacionais. $\mathrm{O}$ surgimento e o desenvolvimento das formas de Estado, das instituições públicas, semipúblicas e privadas não estão inscritos em nenhuma forma de determinismo econômico-natural. Há de fato uma plasticidade inerente às formas sociais que podem ser mobilizadas pelas sociedades humanas para viabilizarem suas condições de produção e de repartição da renda e da riqueza. Não se trata de nenhuma visão construtivista ou voluntarista, mas do reconhecimento da razão, da inteligência e criatividade humanas também para a construção das estruturas produtivas e distributivas que possam assegurar coerência macroeconômica, coesão e justiça sociais e, enfim, maior qualidade de vida para todos os membros da sociedade.

Para superar os obstáculos epistemológicos da concepção positivista em ciências é preciso considerar as implicações que uma abordagem ontológica dos objetos estudados permite detectar. Operacionalmente, significa considerar as especificidades do objeto estudado, suas características constitutivas, seu modo próprio de existir, se reproduzir, transformar-se ou perecer.

A Figura 1 ilustra essa problemática, essencialmente, antipositivista. Trata-se de considerar que a realidade concreta pode ser subdividida em três sistemas (inorgânico, orgânico e social) que se diferenciam por suas propriedades, modo de existência e reprodução específicos. Esse esquema tem por fundamento teórico-metodológico os trabalhos sobre a Ontologia do ser social, desenvolvidos nos

\footnotetext{
${ }^{6}$ Os grifos são nossos.
} 
trabalhos de Georg Lukács. Em As Bases Ontológicas do Pensamento e da Atividade do Homem, Luckas argumenta que, no que concerne às especificidades dos sistemas socioeconômicos:

“[...] não seremos capazes de captar sua especificidade se não compreendermos que um ser social só pode surgir e se desenvolver sobre a base de um ser orgânico e que esse último pode fazer o mesmo apenas sobre a base do ser inorgânico. [...] tornou-se claro que, entre uma forma mais simples de ser (por mais numerosas que sejam as categorias de transição que essa forma produz) e o nascimento real de uma forma mais complexa, existe algo qualitativamente novo, cuja gênese não pode jamais ser simplesmente 'deduzida' da forma mais simples” (Luckács 1978, p. 3)

As letras maiúsculas representam as propriedades, regularidades, comportamentos ou fenômenos encontrados nos sistemas sociais, orgânicos e inorgânicos. Entretanto, as propriedades do tipo A, B e C são específicas, respectivamente, dos sistemas inorgânicos, orgânicos e sociais. Já as propriedades do tipo D são comuns aos sistemas inorgânicos e orgânicos; as do tipo E são encontradas nos três sistemas e as do tipo F são comuns aos sistema sociais e orgânicos.

Tradicionalmente, as ciências recorrem a analogias para a produção de hipóteses e construção de teorias. Esse recurso, porém, é pertinente em razão das propriedades que são comuns aos sistemas. Mas o problema com as analogias é que, ao buscar semelhanças ou padrões análogos de funcionamento, o pesquisador corre o risco de perder de vista as propriedades que são específicas do sistema que estuda. A busca das particularidades, das singularidades, deve ser considerada um expediente fundamental à atividade científica tanto quanto à tentativa de generalização.

Outro ponto a ser destacado refere-se ao grau crescente de complexidade quando o objeto analisado desloca-se do sistema inorgânico para o orgânico e, em seguida, para o socioeconômico. Um limite epistemológico crucial surge quanto as analogias com o sistema inorgânico, ou mais amplamente, com o mundo natural - que produziu a "naturalização dos fenômenos econômicos" -, terminam eliminando as especificidades do objeto econômico em face dos objetos da Física, Química ou Biologia. Nesse sentido, as propriedades do tipo C, que só são encontradas nos sistemas sociais, são perdidas no âmbito das análises, produzindo uma caricatura do real-econômico que reduz ou esvazia completamente o potencial heurístico, explicativo e preditivo das teorias em que se baseiam.

Consequentemente, a insistência positivista na unicidade do método científico e sua recusa a uma apreensão ontológica do objeto analisado conduz não apenas à naturalização dos fenômenos econômicos e, portanto, ao seu desenraizamento da história, mas à não inteligibilidade de propriedades que só existem nos sistemas socioeconômicos. Como observa Latouche (1977), na perspectiva positivista a economia surge como uma dimensão biológica e não como um resultado de relações sociais conscientes de produção e de distribuição que os seres humanos têm 
de manter entre si (divisão do trabalho, distribuição setorial da produção) e com a natureza para viabilizarem sua sobrevivência. Mas essas relações não se enquadram em nenhum esquema invariante no tempo e no espaço, suscetível de ser detectado pelo método experimental ou por outra metodologia científica bem-sucedida nas ciências da natureza.

Figura 1: Os sistemas socioeconômicos são irredutíveis ao funcionamento dos sistemas orgânicos E inorgânicos, seu maior grau de complexidade decorre de propriedades que lhes são específicas

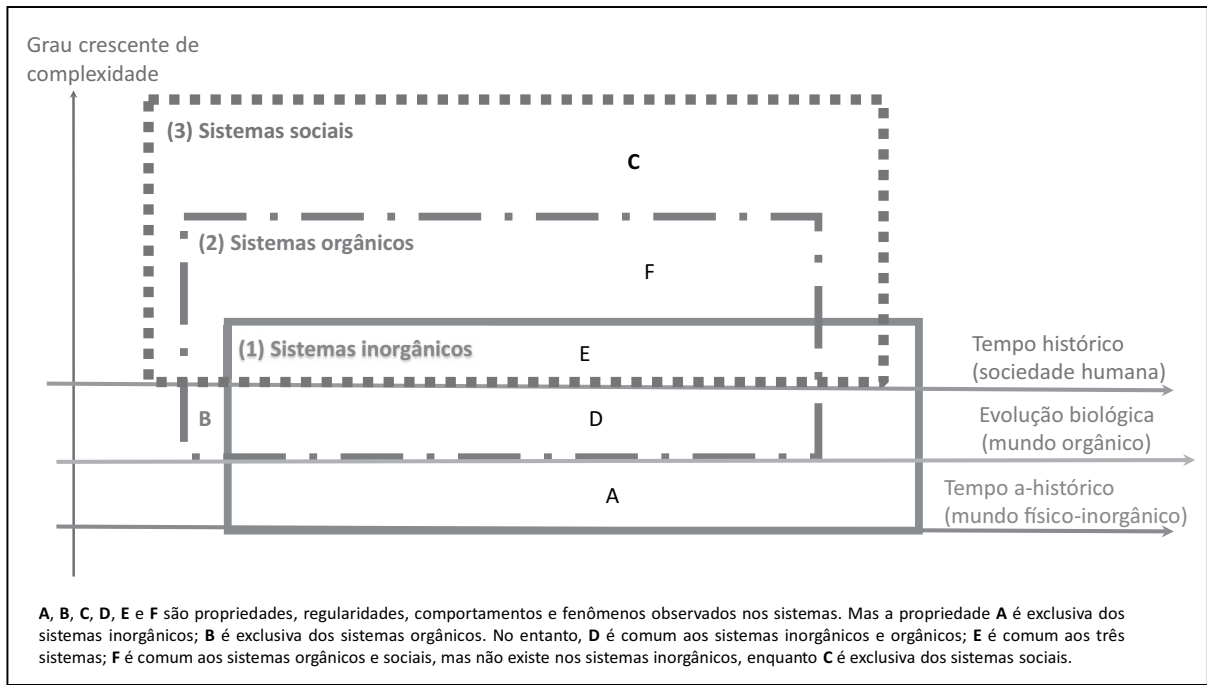

Essa naturalização dos fenômenos econômicos, ou seja, essa ontologia organicista do sistema socioeconômico, quando não esvazia o conteúdo humano da Ciência Econômica, apreende a natureza humana como algo fixo, imutável. Daí a crítica de Morin (2000)

"O conhecimento pertinente é o que é capaz de situar qualquer informação em seu contexto e, se possível, no conjunto em que está inscrita. [...] o conhecimento progride não tanto por sofisticação e abstração, mas, principalmente, pela capacidade de contextualizar e englobar. [...] a Ciência Econômica é a ciência humana mais sofisticada e a mais formalizada. Contudo, os economistas são incapazes de estar de acordo sobre suas predições, geralmente errôneas. Por quê? Porque a Ciência Econômica está isolada das outras dimensões humanas e sociais que lhe são inseparáveis. Como diz Jean-Paul Fitoussi, 'muitos disfuncionamentos procedem hoje, de uma mesma fraqueza da política econômica: a recusa em enfrentar a complexidade'. [...] a política econômica é a mais incapaz de perceber o que não é quantificável, ou seja, as paixões e as necessidades humanas. De modo que a Economia é, ao mesmo tempo, a ciência humana mais avançada matematicamente e a mais atrasada humanamente." 
Os conteúdos ideológicos dessa tentativa de naturalização desumanizante da economia, manifesta desde os fisiocratas, tornam-se, no entanto, flagrantes ao limitar o papel do cientista econômico à detecção de regularidades "naturais" ou "leis puramente econômicas e gerais" para convencer os homens a aceitarem como inescapáveis, porquanto invariantes e necessariamente benéficas ao conjunto da sociedade. Foi essa postura que levou o economista regulacionista Lipietz (1991) a indignar-se, argumentando que:

"os economistas costumam considerar o objeto de seus estudos (nossas sociedades mercantis e salariais) como se pudesse ser definido por um conjunto de leis, comportamentos e tendências eternas. Isso pode valer para a ciência econômica que distribui os Prêmios Nobel: haveria uma organização, perfectível decerto, mas já definitiva em suas linhas gerais, capaz de garantir a máxima eficácia na produção e na distribuição da riqueza, e tal organização seria a nossa!”

Talvez, por isso, dois grandes economistas de posições teóricas e ideológicas opostas expressaram posições convergentes quanto à formação ideal do economista. Para Hayek (apud Libanio, 2002), ninguém pode se tornar um grande economista se for somente economista. E acrescentava que um economista que somente é economista torna-se prejudicial e pode constituir-se num verdadeiro perigo para a sociedade. Keynes foi ainda mais explícito ao considerar que um economista deveria ser um estatístico, um matemático, um historiador, um filósofo. Deveria compreender símbolos e expressar-se bem em palavras. Inteligência penetrante, clareza de ideias e bom-senso são as qualidades que um economista deveria ter. Além disso, para Keynes (apud Buchholz, 2000), o economista:

“[...] Deve contemplar o particular nos termos do genérico, e tocar o abstrato e o concreto na mesma revoada do pensamento. Deve estudar o presente à luz do passado com objetivos futuros. Nenhuma parte da natureza humana ou das suas instituições deve ficar completamente fora do alcance de sua visão. Ele deve ser decidido e desinteressado com a mesma disposição; tão distante e incorruptível quanto um artista, e ainda assim tão perto da terra quanto um político.”

Preocupado com questões práticas relativas ao desenvolvimento econômico, Kaldor (1978, apud Arrous, 1999) argumentava

“[...] eu tento encontrar qual tipo de regularidade pode ser detectada nos fenômenos observados empiricamente e então descobrir quais hipóteses particulares e testáveis poderiam explicar a associação entre as variáveis em questão. [...] Esta abordagem é mais modesta (no sentido de que ela não busca explicações que derivam de um modelo universal do 
sistema econômico) e igualmente mais ambiciosa (no sentido de que ela busca descobrir soluções ou remédios para problemas reais)." 7

Esta abordagem kaldoriana é a utilizada nos trabalhos desenvolvidos pelas análises regulacionistas, objeto da próxima seção.

\section{OS APORTES DA TEORIA DA REGULAÇÃO E DA ECONOMIA SOCIAL DE MERCADO}

O conceito de Economia Social de Mercado (ESM) foi proposto por Müller-Armack (1947, apud Resico, 2012), como denominação para a nova abordagem do desenvolvimento econômico que se afirmara no pós-Segunda Guerra na Alemanha e na Áustria. O enfoque teórico reconhece as falhas alocativas e distributivas do mercado e a possibilidade de o Estado, juntamente com as demais instituições públicas e semipúblicas, regular a relação mercantil com o objetivo de prover as condições necessárias ao bem-estar social. Entretanto, esse objetivo não é exclusivo da ESM, pois as teorias keynesiana e institucionalista também reconhecem a necessidade de regulação das economias capitalistas que são mercantis, monetárias e salariais. Portanto, seus princípios teóricos e políticas que implicam permitem situá-la entre as correntes da análise econômica institucionalista.

Por outro lado, a Teoria da Regulação surge na segunda metade dos anos 1970, a partir de trabalhos que buscavam uma explicação alternativa à da macroeconomia ortodoxa para o esgotamento e crise dos regimes de crescimento fordista. Três influências principais integram as matrizes teóricas do programa de pesquisa regulacionista: a) a teoria marxiana ${ }^{8}$ e a macroeconomia kaleckiana; b) o institucionalismo americano (J. Commons; W. Mitchell; T. Veblen); c) os trabalhos da Nouvelle Histoire, desenvolvidos pela École des Annales (F. Braudel; L. Febvre). Além dessas três correntes, deve-se acrescentar a influência das análises pós-keynesianas, com autores como N. Kaldor e H. Minsky. ${ }^{9}$

Contrariamente a uma crítica vulgar, em geral, proveniente do marxismo ortodoxo, as macroanálises regulacionistas não buscam, nem permitem inferir de seus princípios teóricos, as condições estruturais para abolir as crises e eternizar o capitalismo por meio da regulação adequada de seus mercados. Mesmo que a dialética marxista reconheça que o capital se reproduz através das próprias crises que engendra, é preciso explicitar como isso ocorre no plano concreto das relações

\footnotetext{
${ }^{7}$ Tradução do original francês, de Jean Arrous (1999).

${ }^{8}$ Utiliza-se a expressão "marxiana" para ressaltar que se trata da influência direta do pensamento econômico de Marx e não de suas interpretações veiculadas por um marxismo ortodoxo ou oficial.

${ }^{9}$ No que concerne à área de pesquisa desenvolvida por Michel Aglietta, moeda e macroeconomia financeira, torna-se muito nítida a influência dos trabalhos de Hyman Minsky.
} 
agente-estrutura e como e por que são possíveis os períodos de prosperidade, apesar da tendência imanente às crises.

Uma característica comum entre a TR e a ESM é que ambas reconhecem a possibilidade de restruturação do espaço econômico-mercantil em prol de relações sociais de produção e de distribuição voltadas também para as necessidades humanas e não apenas para e pelos valores de troca. Para as duas abordagens, o sistema socioeconômico é um sistema aberto, sujeito a transformações permanentes, segundo a criatividade das relações indivíduo-agente-estrutura. ${ }^{10}$

$\mathrm{O}$ mercado, entidade central na teoria econômica tradicional, surge como uma construção institucional. Mesmo um mercado concorrencial tem sua viabilidade assentada em instituições e regras de funcionamento muito mais complexas do que supõem as teorias derivadas da abordagem neoclássica em Ciência Econômica.

O Quadro 1 permite uma comparação entre a teoria econômica neoclássica, a TR e a ESM. As relações econômicas estruturam-se num sistema aberto, ontológica e epistemologicamente irredutível aos sistemas fechados, característicos dos fenômenos naturais. Essa abertura significa que tais sistemas não apenas evoluem, mas que o fazem através dos comportamentos humanos, mediante micro e macrorregularidades socioeconômicas que expressam fatores objetivos (derivados do ambiente em que os agentes econômicos atuam), mas também fatores subjetivos (sua consciência, suas interpretações e expectativas quanto ao comportamento dos demais agentes e quanto à evolução de variáveis econômicas que consideram relevantes). ${ }^{11}$

Contribuindo para a fundamentação ontológica da economia como resultado de relações agente-estrutura, mutáveis geográfica e historicamente e, portanto, como objeto não natural, pois socialmente construído, é esclarecedora a percepção do neurocientista Steven Rose (2006):

“[...] nós, seres humanos, somos radicalmente indeterminados - ou seja, vivendo na interface de múltiplos determinismos, nos tornamos livres para construir os nossos próprios futuros, embora sob circunstâncias que não são de nossa escolha. [...] Somos tanto restritos como liberados por nossa natureza biossocial."

\footnotetext{
${ }^{10}$ Para Marx, em O Capital, como a economia mercantil-capitalista necessariamente submete os valores de uso e as necessidades sociais à obtenção e expansão dos valores de troca, não poderia se constituir, verdadeiramente, numa economia humana.

${ }^{11}$ Japiassu (1979) argumenta que "a desgraça das ciências humanas é que lidam com um objeto que fala”. Os seres humanos agem e reagem, possuem autoconsciência que capacitam transformar, as estruturas sobre as quais atuam, inclusive (re)criar suas próprias relações de produção e de distribuição. É, portanto, ao mesmo tempo sujeito e objeto (conscientes) do próprio conhecimento que produz sobre a realidade em que vive.
} 
Quadro 1: A teoria econômica convencional (neoclássica)

em comparação com a ESM e a TR

\begin{tabular}{|c|c|c|}
\hline Teoria Neoclássica & $\begin{array}{c}\text { Economia Social } \\
\text { de Mercado (ESM) }\end{array}$ & Teoria da Regulação (TR) \\
\hline $\begin{array}{l}\text { Sistema econômico assimi- } \\
\text { lado a sistemas fechados, } \\
\text { análogo à mecânica clássica } \\
\text { newtoniana. }\end{array}$ & $\begin{array}{l}\text { Sistema econômico consi- } \\
\text { derado um sistema aberto, } \\
\text { sujeito a transformações } \\
\text { permanentes, segundo a } \\
\text { criatividade das relações } \\
\text { indivíduo-agente-estrutura. }\end{array}$ & $\begin{array}{l}\text { Sistema econômico considerado um } \\
\text { sistema aberto e complexo, sujeito a } \\
\text { transformações permanentes, segundo } \\
\text { a criatividade das relações indivíduo- } \\
\text {-agente-estrutura. }\end{array}$ \\
\hline $\begin{array}{l}\text { Mercado como um meca- } \\
\text { nismo: a concorrência é um } \\
\text { atributo inerente e natural. }\end{array}$ & $\begin{array}{l}\text { Mercado como um proces- } \\
\text { so: a concorrência é um } \\
\text { atributo construído institu- } \\
\text { cionalmente. }\end{array}$ & $\begin{array}{l}\text { O mercado surge como um resultado } \\
\text { das interações dos agentes econômicos } \\
\text { e de suas instituições. }\end{array}$ \\
\hline $\begin{array}{l}\text { Economia como ciência } \\
\text { neutra, segundo os princí- } \\
\text { pios axiológicos da doutrina } \\
\text { positivista. }\end{array}$ & $\begin{array}{l}\text { A atividade humana é uma } \\
\text { unidade em si. A dimensão } \\
\text { econômica não pode ser } \\
\text { compreendida quando } \\
\text { dissociada das demais di- } \\
\text { mensões sociais, culturais, } \\
\text { éticas e antropológicas. }\end{array}$ & $\begin{array}{l}\text { O objeto econômico é um objeto cons- } \\
\text { truído pelas ações práticas de indivíduos, } \\
\text { agentes coletivos e suas instituições. } \\
\text { Diferentemente das leis naturais, as "leis } \\
\text { econômicas" como expressão de regu- } \\
\text { laridades comportamentais não existem } \\
\text { independentemente da sociedade e da } \\
\text { atividade humana. }\end{array}$ \\
\hline $\begin{array}{l}\text { Comportamento econômico } \\
\text { baseado na escassez, em } \\
\text { análises de estática com- } \\
\text { parativa. }\end{array}$ & $\begin{array}{l}\text { Escassez é relativa e ne- } \\
\text { cessidades não equivalem } \\
\text { a desejos. As inovações } \\
\text { tecnológicas e organizacio- } \\
\text { nais permitem ganhos de } \\
\text { produtividade e a superação } \\
\text { da escassez como atributo } \\
\text { absoluto. }\end{array}$ & $\begin{array}{l}\text { As tendências da produtividade e da de- } \\
\text { manda permitem o crescimento econô- } \\
\text { mico cumulativo com base nos ganhos } \\
\text { dinâmicos crescentes de escala. }\end{array}$ \\
\hline
\end{tabular}

A Economia Social de Mercado e a Teoria da Regulação possuem mais pontos de convergência e de contato do que de divergência fundamental. Isso se deve também à ontologia que compartilham acerca dos papéis do mercado nas economias do século 21. Como não há nenhuma "lei" ou regularidade econômica inescapável - já que o conhecimento científico existe em sua aplicabilidade também para o mundo socioeconômico, sobretudo porque este último funciona a partir das relações sociais -, a sociedade pode mobilizar instituições, leis, normas, regras e convenções que permitem moldar os comportamentos mercantis, readequando-os aos interesses sociais.

Aglietta (1997), um dos autores fundadores da Escola da Regulação, argumenta que a dinâmica do capitalismo é uma força produtiva gigantesca, mas é também uma potência cega, na medida em que não é capaz por si mesma de garantir as condições da reprodução sistêmica no nível macroeconômico. Para este autor, o capitalismo tem a capacidade de mobilizar as energias humanas para as transformar em crescimento e expansão da riqueza acumulada. Mas, em razão dos choques dos interesses individuais em que se baseia, ele não tem a capacidade de 
conferir, de forma espontânea e automática, coerência global ao conjunto do sistema econômico. E isso porque os interesses mercantis não estão voltados para a satisfação de necessidades humanas em geral e independentemente do poder aquisitivo dos agentes econômicos. Não podem, portanto, serem sociais ex ante, pois, do contrário, a produção para o lucro mercantil seria inviável em seus pressupostos. Como se sabe, a produção é viabilizada pelo e para o valor de troca (preço de venda monetário máximo) e não pelo valor de uso (propriedade dos bens para satisfazer necessidades e demandas sociais). Por isso, os inúmeros exemplos de conflito entre a lógica mercantil e os interesses da sociedade. Os interesses dos mercados ou das empresas não coincidem, sempre e necessariamente, com os interesses do conjunto da população. E essa argumentação é válida mesmo que não se considere a questão ambiental, cuja pertinência e atualidade vem problematizar ainda mais as interações mercado-sociedade mediada pelo Estado.

Entre os economistas regulacionistas, Boyer se destaca por seu programa de pesquisa dedicado à construção de uma macroeconomia histórica e institucionalista, fora da concepção natural-positivista e dos cânones neoclássicos. Em Peut-on mettre en evidence des lois en Économie? Un éclairage régulationniste (2007, p. 6), ele sustenta:

“[...] de um lado, as propriedades de um sistema econômico são estritamente condicionadas pela natureza dos processos de coordenação, das instituições econômicas, das normas jurídicas e dos compromissos sociais. São tantos fatores que fazem intervir de forma privilegiada as instâncias políticas. Não se pode portanto esperar leis análogas a estas das ciências da natureza porque elas são abertas sobre concepções políticas, jurídicas, éticas que vêm retroagir sobre os ajustamentos econômicos. De outro lado, as eventuais regularidades, observáveis empiricamente, são elas mesmas contingentes a um espaço econômico dado e a um período preciso: tal é o ensinamento de meio século de análises macroeconômicas. Além disso, elas não são observáveis senão por um período delimitado pois elas se desestabilizam pelas crises ou são renovadas através de uma série de inovações maiores." ${ }^{2}$

Boyer conclui que a maior ênfase atual em trabalhos empíricos na prática dos economistas é bem-vinda porque ela tende a fazer da economia uma disciplina de observação e não somente uma ciência nomológica ou normativa. Mas, continua o autor, “[...], entretanto, está-se longe do ideal de uma Física Econômica que reconciliaria construção teórica com dados da observação". Consequentemente, "os economistas deveriam se libertar do modelo das ciências da natureza e abandonar a ideia de uma matemática econômica ou de uma física social como objetivo e método de explicação das 'leis econômicas'”. A atividade econômica está inserida

${ }^{12}$ Grifos do autor. 
em uma rede de representações sociais, normas jurídicas e de intervenções públicas que estão longe de ter por objetivo exclusivo a alocação ótima de recursos escassos, tal como supõe a teoria econômica-padrão de base neoclássica e walrasiana. Este autor observa ainda que a situação torna-se mais explícita quando o pesquisador volta-se para a análise das crises e dos ciclos econômicos, pois o economista não dispõe da lista de leis econômicas (trans-históricas e independentes das ações humanas) para reger as grandes transformações econômicas.

Partindo dessa perspectiva epistemológica, as análises regulacionistas exploram um espaço teórico intermediário entre as supostas "leis gerais" (que as teorias ortodoxas consideram válidas para todo regime de crescimento econômico) e a simples observação de regularidades empíricas. Entre grande teoria e pura descrição pode-se recorrer à formalização, em seguida, ao teste empírico dos regimes de crescimento e de acumulação de capital, buscando caracterizar as estruturas institucionais que definem seus correspondentes modos de regulação. Assim, a metodologia regulacionista permite construir esse espaço intermediário sobre o qual é possível e legítimo a tentativa de encontrar regularidades. Entretanto, tais regularidades permaneceriam historicamente datadas e geograficamente situadas. Essa posição é também defendida por Bresser-Pereira (2009, p. 174):

"Para estudar sistemas econômicos complexos e em mudança, o método científico adequado é o método histórico-dedutivo. É histórico, porque se baseia na observação da realidade econômica histórica, onde cada evento é único, mas está suficientemente relacionado a outros eventos econômicos, de tal forma que é possível buscar regularidades ou pelo menos tendências. [...] Assim, ao contrário do economista neoclássico que vê a economia como uma "ciência natural", essa abordagem histórica exige que o pesquisador inclua na realidade social e econômica que é objeto de seus modelos explicativos as convenções, rotinas ou instituições, [...]." ${ }^{13}$

A Teoria da Regulação e a Economia Social de Mercado reconhecem a capacidade humana de estabelecer estruturas socioeconômicas mais consentâneas com as demandas sociais. Mas essas estruturas não podem ser derivadas de nenhum princípio econômico trans-histórico ou de mecanismos puramente mercantis e naturais, independentes da consciência e da racionalidade contextual dos agentes individuais e coletivos. O Quadro 2 faz uma comparação entre os princípios e proposições da Teoria da Regulação e a Economia Social de Mercado.

${ }^{13}$ Grifos do autor. 
Quadro 2: Comparação entre os princípios e proposições da ESM e daTR

\begin{tabular}{|c|c|}
\hline Economia Social de Mercado (ESM) & Teoria da Regulação (TR) \\
\hline $\begin{array}{l}\text { Concepção aberta, pois a teoria deve acompanhar } \\
\text { as mudanças estruturais e as novas condições } \\
\text { socioeconômicas. }\end{array}$ & $\begin{array}{l}\text { Concepção aberta, pois os modos de regulação, } \\
\text { como estruturas institucionais, refletem as trans- } \\
\text { formações socioeconômicas. }\end{array}$ \\
\hline $\begin{array}{l}\text { O mercado é o melhor sistema de alocação de re- } \\
\text { cursos, mas deve ser corrigido e provido de con- } \\
\text { dições institucionais, éticas e sociais adequadas } \\
\text { para sua operação eficiente e equitativa. }\end{array}$ & $\begin{array}{l}\text { As economias capitalistas não são apenas mer- } \\
\text { cantis, são também monetárias e salariais. A } \\
\text { combinação de mercados, moeda e trabalho é } \\
\text { complexa, portadora de inúmeros conflitos, o que } \\
\text { exige a interveniência das instituições reguladoras, } \\
\text { como fatores de estabilidade e sustentabilidade } \\
\text { dos sistemas econômicos. }\end{array}$ \\
\hline $\begin{array}{l}\text { Estado e mercado devem estar a serviço das de- } \\
\text { mandas sociais e não o contrário. }\end{array}$ & $\begin{array}{l}\text { As economias mais eficientes em termos econô- } \\
\text { micos e sociais são aquelas que reconhecem a } \\
\text { complementaridade das ações do Estado com o } \\
\text { mercado. }\end{array}$ \\
\hline $\begin{array}{l}\text { São necessários "princípios estruturais" e "princí- } \\
\text { pios reguladores" para que a lógica mercantil seja } \\
\text { portadora de benefícios sociais. }\end{array}$ & $\begin{array}{l}\text { O conceito de modo de regulação, histórica e } \\
\text { geograficamente situado, reflete a arquitetura } \\
\text { institucional que estrutura e regula as economias } \\
\text { nacionais. }\end{array}$ \\
\hline $\begin{array}{l}\text { Controle da Inflação, geração de emprego e } \\
\text { crescimento econômico devem ser objetivos das } \\
\text { políticas anticíclicas do Estado. }\end{array}$ & $\begin{array}{l}\text { Os modelos e estratégias de desenvolvimento } \\
\text { socioeconômico são viáveis apenas quando } \\
\text { combinam coerência macroeconômica com coe- } \\
\text { são social. Estes últimos dependem de políticas } \\
\text { econômicas que busquem, simultaneamente, } \\
\text { estabilidade de preços, geração de emprego e o } \\
\text { crescimento econômico. }\end{array}$ \\
\hline $\begin{array}{l}\text { São necessárias políticas sociais para fortalecer } \\
\text { os grupos com desvantagens e afirmar a igual- } \\
\text { dade de oportunidades. Mercados livres e con- } \\
\text { correnciais não são suficientes para resolver os } \\
\text { problemas de equidade na distribuição de renda } \\
\text { e da riqueza. }\end{array}$ & $\begin{array}{l}\text { Os compromissos institucionalizados emergem } \\
\text { das interações entre Estado e os atores sociais, } \\
\text { com o objetivo de criar as condições para uma } \\
\text { distribuição mais equitativa da renda e da riqueza. } \\
\text { Eles são essenciais para viabilizar a compatibili- } \\
\text { zação da lógica mercantil com as necessidades } \\
\text { sociais. }\end{array}$ \\
\hline $\begin{array}{l}\text { A ênfase deve recair sobre os problemas estrutu- } \\
\text { rais das economias. A política econômica não de- } \\
\text { ve ser absorvida inteiramente pelas necessidades } \\
\text { da conjuntura. }\end{array}$ & $\begin{array}{l}\text { Como a política econômica depende da insti- } \\
\text { tucionalidade, na qual o modo de regulação se } \\
\text { baseia, os fatores estruturais são determinantes } \\
\text { do sucesso tanto da política econômica quanto } \\
\text { das estratégias nacionais de desenvolvimento } \\
\text { socioeconômico. }\end{array}$ \\
\hline $\begin{array}{l}\text { Busca combinar o princípio da liberdade de mer- } \\
\text { cado com o princípio da equidade social. }\end{array}$ & $\begin{array}{l}\text { Liberdade e eficiência econômicas pressupõem } \\
\text { estabilidade das relações sociais e elevação dos } \\
\text { níveis de vida das populações. }\end{array}$ \\
\hline
\end{tabular}




\section{CONCLUSÃO}

Os fenômenos econômicos surgem do necessário metabolismo ser humano-natureza, base da sobrevivência da espécie humana. Nessa perspectiva, a Economia é um subconjunto de um sistema muito mais amplo e complexo, estruturado pela conjunção das esferas inorgânica, orgânica e social. Esse subsistema é composto de relações de produção e de distribuição do produto entre os diversos setores, agentes e demais participantes do processo produtivo. Entretanto, a natureza tem sido convertida pela economia em objeto de valorização de riqueza, inviabilizando o surgimento de relações econômicas em simbiose com o meio ambiente e com os próprios seres humanos entre si. Diferentemente do que ocorre no mundo físico-biológico, no mundo social os seres humanos são simultaneamente meio e fim, objeto e sujeito das estruturas de produção e de distribuição. Os critérios positivistas de objetivação e neutralidade científica não são apenas inadequados à produção de conhecimento econômico pertinente, são impossíveis de ser aplicados sem se degenerar em um expediente ideológico, pois legitimador da forma dominante de se estruturar as relações econômicas em prol de grupos, classes sociais ou setores de atividade.

Como produto das concepções positivistas em ciências sociais, a teoria econômica neoclássica e suas variantes contemporâneas não empreendem nenhuma ruptura com o naturalismo que marcou o pensamento econômico fisiocrático e clássico. Nos termos da epistemologia de Bachelard, elas não realizam nenhum corte epistemológico que implicaria reconhecer as bases ontológicas próprias aos sistemas sociais e empreender uma ruptura efetiva com a concepção "fisicalista" de se produzir conhecimento econômico. Evidentemente, numa tal concepção, a historicidade das análises não tem nenhuma relevância teórica. Elementos históricos, quando mobilizados, não passam de simples ingredientes de contextualização de teorias e modelos supostamente válidos em todos os tempos e lugares.

A irredutibilidade do objeto econômico aos objetos da Física, Química ou Biologia faz da ciência econômica uma ciência histórica, significando que os seres humanos agem e reagem, transformam seu meio ambiente e as estruturas sobre as quais atuam. Se estão sujeitos a estruturas herdadas, condicionamentos múltiplos e restrições naturais, possuem a capacidade de ação transformadora e criadora que lhes conferem autonomia, mesmo que relativa, mas suficiente para produzirem sistemas socioeconômicos que poderiam ser compatíveis com os valores humanos básicos.

A Teoria da Regulação compartilha com a Economia Social de Mercado a multiplicidade de formas possíveis de organização das relações sociais de produção e de distribuição através do tempo histórico e entre diferentes espaços geográficos. Essas formas socioeconômicas não podem ser inferidas de uma visão axiomática baseada na trilogia "programas de otimização - expectativas - equilíbrios de mercado", como se pudessem existir independentemente das relações sociais que as determinam. Para as análises regulacionistas, o conceito de racionalidade pertinente é o de racionalidade situada ou contextual, expressão teórica das rela- 
ções agente-estrutura enquanto base da economia e de suas formas possíveis de evolução.

Conforme Japiassu (1979), a Ciência Econômica deve ser classificada dentre as ciências praxeológicas, isto é, ciências que participam simultaneamente do descritivo (explicativo) e do normativo (ação regulatória, intervenção, política econômica). Isso significa que a Economia não pode se constituir numa ciência puramente lógico-dedutiva com base em uma axiomática trans-histórica para a construção de modelos econômicos e teorias universais.

O capitalismo é o modo de produção dominante na atualidade, reproduzindo-se através de suas múltiplas variantes nacionais, tanto em formações socioeconômicas desenvolvidas, quanto em desenvolvimento ou subdesenvolvidas. A ESM e a TR podem contribuir para aperfeiçoá-lo do ponto de vista social e mesmo ambiental, o que implica torná-lo mais justo ou mais humano apesar das resistências políticas e dos fatores que lhes são endógenos. Mas essas duas abordagens não devem pretender constituir-se em teorias da perenidade de apenas uma, dentre muitas outras formas possíveis e historicamente determinadas, de se produzir e distribuir os resultados da produção, o capitalismo, desde que haja regulação adequada dos diversos mercados que lhes são os eixos de funcionamento. Desde que os seres humanos surgiram no planeta, muitos modos de produção se sucederam na história longa e não há nenhum fundamento teórico ou empírico para eternizá-lo, sob qualquer pretexto político-ideológico, como propôs Fukuyama (1992). O horizonte histórico está sempre aberto ao novo, à atividade criadora da espécie humana, por isso a Economia emerge no plano das civilizações como objeto socialmente construído, dadas às restrições do meio ambiente, do desenvolvimento científico-tecnológico e dos conflitos sociopolítico-institucionais subjacentes.

\section{REFERÊNCIAS BIBLIOGRÁFICAS}

Aglietta, Michel. (1997) “Le capitalisme au tournant du siècle - la théorie de la régulation à l'épreuve de la crise”. Posfácio da nova edição de Régulation et Crises du Captialisme. Paris: Odile Jacob.

Arrous, Jean. (1999) Les Théories de la Croissance. Paris: Éditions du Seuil.

Bachelard, Gaston (1996) A Formação do Espírito Científico. Contribuição para uma Psicanálise do Conhecimento. Rio de Janeiro: Contraponto.

Blaug, Mark (1998) “Os problemas com o formalismo”. Entrevista para Revista Challenge, maio-junho.

Boyer, Robert (2007) “Peut-on mettre en evidence des lois en Économie? Un éclairage régulationniste.” PSE Working Papers, n. 2007-44. Hal archives-ouvertes.fr.

Bresser-Pereira, L.C. (2009) “Os dois métodos e o núcleo duro da teoria econômica”. Revista de Economia Política 29 (2), 2009.

Buchholz, Todd (2000) Novas Ideias de Economistas Mortos. São Paulo: Record.

Castoriadis, Cornelius (2008) As Encruzilhadas do Labirinto. São Paulo: Paz e Terra.

Fukuyama, Francis (1992) The End of History and the Last Man. Canada: Free Press, Maxwell Macmillan.

Japiassu, Hilton (1979) Introdução ao Pensamento Epistemológico, Rio de Janeiro: Editora Francisco Alves. 
Kaldor, Nicolas (1978) Collected Economic Essays. Volume 5: Further Essays on Economic Theory, London: Duckworth, pp. VII-XXIX.

Latouche, Serge (1977) Análise Econômica e Materialismo Histórico. Rio de Janeiro: Zahar.

Libanio, João Batista (2002) A Arte de Formar-se. São Paulo: Edições Loyola.

Lipietz, Alain (1991) Audácia: Uma Alternativa para o Século 21. São Paulo: Nobel.

Löwy, Michel (1994) As Aventuras de Kalr Marx contra o Barão de Münchhausen: Marxismo e Positivismo na Sociologia do Conhecimento. São Paulo: Cortez.

Luckács, Georg (1978) "As bases ontológicas do pensamento e da atividade do homem”. Temas de Ciências Humanas, (tradução de Carlos Nelson Coutinho), São Paulo: Livraria Editora Ciências Humanas, n. 4, p. 1-18, 1978.

Morin, Edgar (2000) Os Sete Saberes Necessários à Educação do Futuro, São Paulo: Cortez.

Popper, Karl (1980) A Miséria do Historicismo. São Paulo: Edusp.

Resico, Marcelo F. (2012) Introdução à Economia Social de Mercado. Rio de Janeiro: Konrad Adenauer Stiftung.

Rose, Steven (2006) O Cérebro do Século XXI. Rio de Janeiro: Editora Globo. 